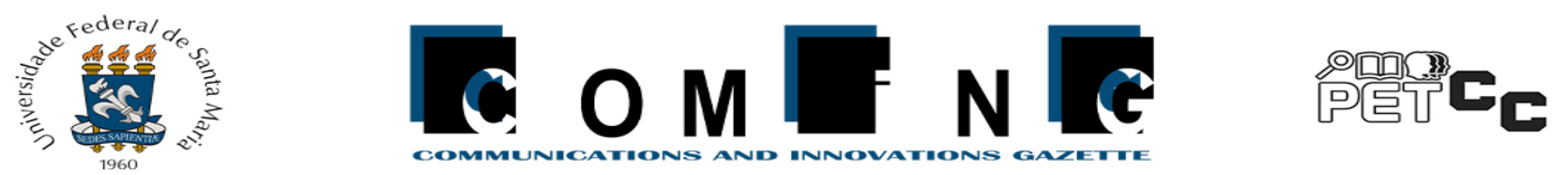

\title{
Sou Mulher e Posso: projeto de inclusão social e de gênero por meio do ensino de instalações elétricas residenciais para moradoras da Ocupação Nova Santa Marta da cidade de Santa Maria - RS
}

\author{
Ana J. Ziegler ${ }^{2}$, Andressa W. Kreutz ${ }^{1}$, Julia C. Madaloz ${ }^{1}$, \\ Natanael R. Gomes ${ }^{1}$ Tainá Lersch $^{1}$, Viviane L. S. de Lima ${ }^{1}$ \\ ${ }^{1}$ Programa de Educação Tutorial Engenharia Elétrica \\ Universidade Federal de Santa Maria (UFSM) \\ CEP 97105-900 - Santa Maria - RS - Brasil \\ ${ }^{2}$ Programa de Pós-Graduação em Geografia - Universidade Federal de Santa Maria

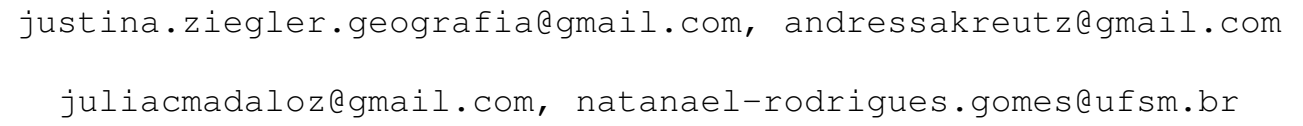 \\ tainalersch.ufsm@gmail.com, vivianelsdelima@gmail.com
}

\begin{abstract}
The project "Sou Mulher e Posso", accomplished in 2018, approached the importance of female protagonism in the effectuation of urban space. The goal was to bring knowledge to 10 residents of the Nova Santa Marta from Santa Maria (RS) occupation about the basics of residential electrical installations, the necessary security in this work and daily aspects related to electricity, so that they get more confidence to perform tasks culturally assigned to men. The project was developed by 10 students from the Electric Engineering Tutorial Education Program (PET-EE) of Federal University of Santa Maria in partnership with 3 students from the Social Communication course and a Master's student in the Geography Graduate Course.
\end{abstract}

Resumo. O projeto "Sou Mulher e Posso", realizado em 2018, abordou a importância do protagonismo feminino na construção do espaço urbano. $O$ objetivo foi levar conhecimento à 10 moradoras da ocupação Nova Santa Marta de Santa Maria (RS) sobre noções básicas de instalações elétricas residenciais, a segurança necessária neste trabalho e aspectos cotidianos vinculados a eletricidade, a fim de que as mesmas sentissem mais confiança para realizar tarefas atribuídas culturalmente aos homens. O projeto foi desenvolvido por 10 alunas do Programa de Educação Tutorial Engenharia Elétrica (PET-EE) da Universidade Federal de Santa Maria em parceria com 3 alunas do curso de Comunicação Social e uma mestranda da Pós-Graduação em Geografia.

\section{Introdução}

A ocupação Nova Santa Marta é composta por sete vilas: 07 de dezembro, 18 de abril, 10 de outubro, Pôr do Sol, Núcleo Central, Alto da Boa Vista e Marista I e II. E apenas no começo do ano de 2020 as famílias moradoras da Nova Santa Marta conseguiram a concessão de posse da terra urbana. 
O pertencimento local e a valorização pessoal das mulheres periféricas se perdem na alienação da mídia. Ao propor que se faça uma reflexão sobre a importância de ser mulher, além de fazer parte da história local, é possível evidenciar as pequenas ações sociais dentro de uma comunidade.

Mesmo com a presença cada vez maior das mulheres no mercado de trabalho, elas continuam recebendo salários menores que dos homens e exercendo atividades inferiores geralmente longe dos espaços de decisão. Uma das explicações para esse caso pode estar atrelada ao contexto histórico no qual as atribuições das mulheres estão relacionadas às atividades que remetem ao cuidado do outro, seja no seu papel de mãe ou no de responsável pelos membros da família.

Levando em conta o que foi dito anteriormente reuniu-se o Laboratório de Espacialidades Urbanas (LABEU) e o Programa de Educação Tutorial Engenharia Elétrica (PET-EE), para a realização de atividades que visem contribuir na modificação desse cenário. O LABEU existe desde 2009 e as áreas de pesquisas são: Geografia Urbana, Gênero, Cultural, social e Humanista. O PET-EE da Universidade Federal de Santa Maria (UFSM) existe desde 1995 e desenvolve projetos de pesquisa, ensino e extensão voltados ao curso de Engenharia Elétrica e a comunidade que está inserido.

Neste contexto, elaborou-se o projeto "Geografia de Gênero e Engenharia Elétrica: o desafio da interdisciplinaridade através da teoria e prática de instalações elétricas residenciais para moradoras da Ocupação Urbana Nova Santa Marta da Cidade de Santa Maria RS", que ficou popularmente conhecido como "Sou Mulher e Posso". O objetivo principal deste projeto foi transformar o cotidiano de um grupo de mulheres moradoras da Ocupação Nova Santa Marta, em Santa Maria-RS, através de uma interação entre o estudo da Geografia de Gênero e as práticas de instalações elétricas.

Em vista disso, promoveu-se a reflexão e prática de questões e atividades vinculadas a eletricidade, de modo a contribuir no cotidiano dessas mulheres, as quais vivem em situação de vulnerabilidade social. A aprendizagem da eletricidade básica, além da promoção à independência mínima dessas mulheres, faz com que se contribua na quebra de papéis que estão impostos em nossa sociedade patriarcal.

O projeto foi desenvolvido por dez alunas do PET-EE da UFSM, responsáveis por ministrar as aulas e produzir os materiais utilizados; três alunas do curso de Comunicação Social, encarregadas da identidade visual, diagramação do material elaborado e divulgação nas mídias sociais; e uma mestranda da Pós-Graduação em Geografia, que concebeu a ideia inicial. Dessa forma, foi possível abranger dez moradoras da ocupação Nova Santa Marta.

O presente trabalho apresenta o desenvolvimento do projeto descrito, desde a etapa de pesquisas até a descrição dos resultados obtidos, sendo composto de fundamentação teórica, metodologia, resultados e considerações finais.

\section{Fundamentação Teórica}

Para discutir gênero como uma categoria, nesta pesquisa, o uso da pesquisadora [Scott 1989] faz com que se construa uma perspectiva de gênero remetente ao conhecimento sobre a diferença sexual. Conhecimento entendido como: sempre relativo; produzido por meios complexos, isto é, por amplos e complexos quadros epistêmicos e 
referindo-se não apenas às ideias, mas, às instituições e estruturas, práticas cotidianas, rituais, enfim, tudo aquilo que constituiria as relações sociais.

Segundo [Scott 1989], gênero é a organização social da diferença sexual. Não refletindo ou implementando diferenças físicas e naturais entre homens e mulheres, gênero seria o conhecimento que estabelece significações para diferenças corpóreas. Mulher, como grupo ou categoria, para Scott, e se bem interpretada, não teria um estatuto de objeto em si mesmo, mas sim através de um instrumento analítico - gênero - com múltiplas e complexas significações.

Ainda em conformidade com [Scott 1989] é possível compreender que as diferenças entre os sexos constituem um aspecto primário da organização social e que são fundamentalmente culturais. Desta forma, a cultura é entendida não só como produções de indivíduos ou coletividades, mas como significações múltiplas, sentidos contraditórios e aspectos normativos. Ela argumenta que "o conceito de gênero foi criado para opor-se a um determinismo biológico nas relações entre os sexos, dando-lhes um caráter fundamentalmente social e o gênero enfatizava igualmente o aspecto relacional das definições normativas da feminidade".

Este aspecto relacional advém da preocupação de estudos feministas que se centravam sobre as mulheres de maneira estreita, assim, a noção de gênero daria conta de que as mulheres e os homens eram definidos. Além disso, o gênero enquanto categoria de análise teria a vantagem de propor uma transformação dos paradigmas do conhecimento tradicional, não apenas acrescentando novos temas, mas, impondo "um reexame crítico das premissas e dos critérios do trabalho científico existente" [Scott 1989].

As intenções de articular a ocupação urbana Nova Santa Marta com lutas femininas sempre se basearam no alcance de condições de igualdade, todavia, a própria organização política era baseada em um modelo masculino e de poder patriarcal. Ocorre que desde as sociedades pré-capitalistas, as mulheres participavam do sistema produtivo, embora jurídica, social e politicamente estivessem em condição inferior ao homem.

De acordo com [Saffioti 2013] "enquanto a produtividade do trabalho é baixa (isto é, enquanto o processo de criação da riqueza social é extremamente lento), não se impõe à sociedade a necessidade de excluir as mulheres do sistema produtivo". Entretanto, o processo de sua expulsão do sistema produtivo já está esboçado na forma subsidiária assumida pelo trabalho das mulheres. Tanto na economia feudal quanto na economia de burgo, e sobretudo nesta última, que prepara o advento da economia urbana, fabril, o emprego da força de trabalho feminina encontra sérias barreiras. Tais entraves impedem, segundo [Saffioti 2003], "a inserção das mulheres ou oferecendo-lhes as posições subalternas e menos compensadoras, as corporações de ofícios, mais do que a economia agrária da época medieval, conduzem o processo de marginalização da mulher do sistema produtivo a uma etapa mais avançada".

Observa-se, portanto, que as determinações de gênero já se inseriram no funcionamento das sociedades classistas, tendo em vista que o modo de produção capitalista não criou a desigualdade entre os gêneros, mas a aprofundou de forma considerável. Deste modo, estes fatores assim como a raça não contêm a explicação da totalidade, sendo, portanto, relacionados às relações de classe.

Havia uma exclusão do gênero feminino da arena dos direitos civis, do Estado de 
direito. Nossa sociedade é machista e reforça essa dominação, discriminando as mulheres. Assim como se vê minoria das mulheres no Estado, não difere-se no ramo da Engenharia em todo o país. Segundo [Lombardi 2006], em termos relativos, a participação das mulheres nos empregos formais dessa profissão não chegou a duplicar durante os 17 anos considerados: de 8,6\% em 1985, atingiu 14,3\% em 2002, o que denota que a engenharia continua sendo um espaço profissional eminentemente masculino no Brasil. Conjuntamente, a estruturação cultural se deu, no geral, com escassez de motivação familiar e social para que meninas e mulheres sigam em áreas consideradas de protagonismo masculino.

Contudo, esse quadro de dominação vem aos poucos sendo modificado: as mulheres estão ganhando espaço a cada dia e mostrando que são capazes de sair da esfera privada para a pública. Da mesma forma que as mulheres estão ocupando lugar no ramo da Engenharia, como mostra o Censo da Educação Superior 2016, eram 291.463 mulheres fazendo graduação em engenharia no Brasil, o que correspondia a 28,3\% dos estudantes que optam por esse curso superior no país, há empresas prestadoras de serviços de manutenção e reformas adentrando ao mercado com apenas profissionais mulheres.

Assim sendo, ressalta-se a importância de atividades que promovam o engajamento e visibilidade da atuação de mulheres em áreas que, até então, apresentam pouca representatividade feminina.

\section{Metodologia}

\subsection{Pesquisa-Ação}

A pesquisa-ação consiste em uma investigação de um problema ou situação relacionado com uma realidade social, sendo analisada com base na experiência e na observação. Uma ação deve ser empregada nessa metodologia, sendo que tal não deve ser trivial, mas sim problemática, de forma que mereça ser investigada, justificando a sua elaboração e condução. Neste método de pesquisa, os pesquisadores atuam de forma ativa realizando o acompanhamento, a análise e a solução dos problemas encontrados durante a realização da ação. Tanto os pesquisadores quanto as pessoas envolvidas na situação estudada devem ser participativos e cooperativos. Além disso, o conhecimento de todos os envolvidos será amplificado durante esse processo [Thiollent 1986]. Tendo em vista a proposta do projeto, a pesquisa-ação foi a metodologia escolhida como base para o desenvolvimento do mesmo.

\subsection{Desenvolvimento do projeto}

O projeto contou com a participação de 10 mulheres da ocupação urbana Nova Santa Marta. As oficinas aconteceram aos sábados em um espaço físico disponibilizado pelo Colégio Marista Santa Marta. Ao todo, ocorreram cinco encontros, nos primeiros foram abordados assuntos teóricos básicos e nos encontros seguintes, foram realizadas as oficinas práticas.

$\mathrm{Na}$ primeira aula foram apresentados conceitos de tensão, corrente, resistência, potência, condutores, isolantes, além de noções de geração, transmissão e distribuição de energia elétrica. Explicou-se também o que é choque elétrico, e a diferença entre os condutores fase, neutro e terra. Na segunda aula ensinou-se a entender a conta de energia, 
introduzindo conceitos de eficiência energética de aparelhos residenciais. Na terceira aula abordaram-se questões sobre segurança básica com eletricidade, foram apresentadas as ferramentas e os instrumentos de medição, sendo que ao final da aula foram realizadas práticas de emendas e de isolação de condutores. Na quarta e na quinta aula ocorreram as práticas de instalações de lâmpadas, de interruptores e de tomadas. Na Figura 1 é possível observar um momento de uma aula prática sendo realizada pelas mulheres.

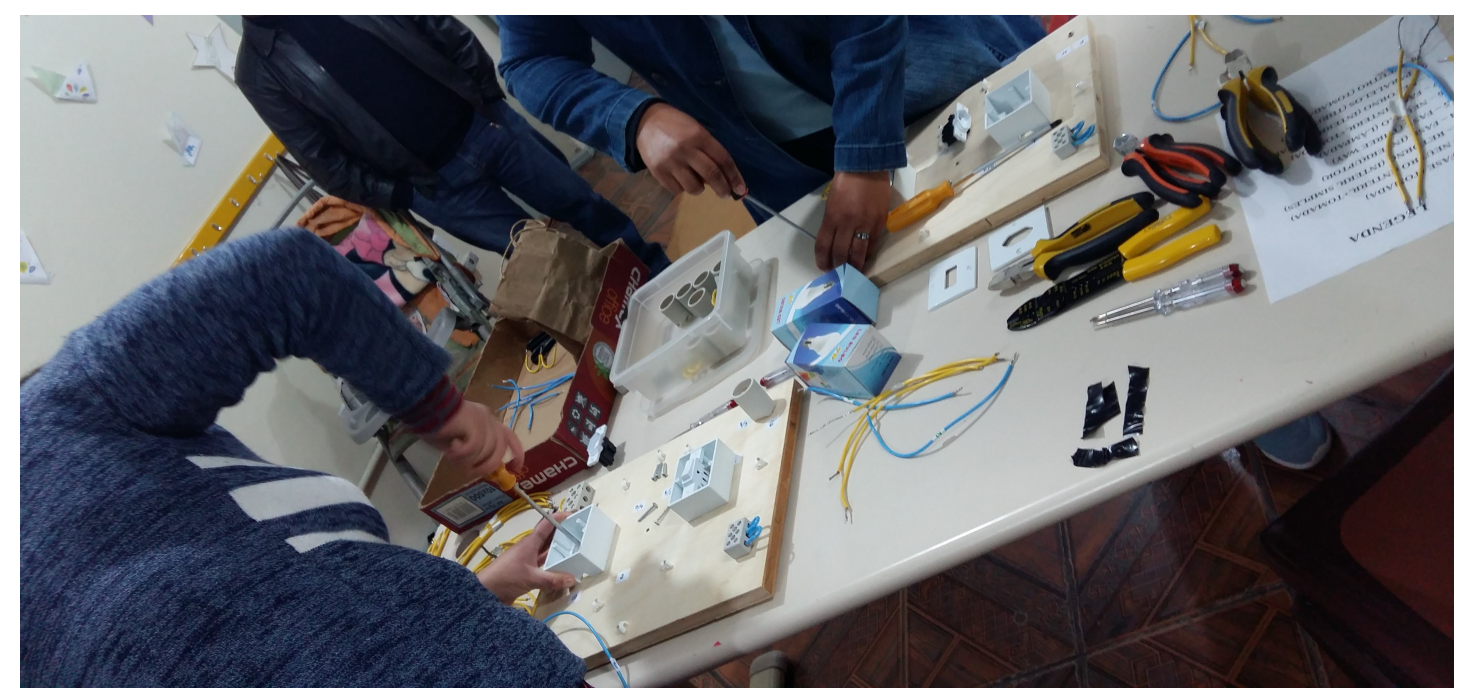

Figura 1. Demonstração de um momento de realização das práticas.

Como a realização da oficina ocorreu em um ambiente sem acesso a laboratórios de instalações elétricas, surgiu a necessidade da elaboração de bancadas didáticas que tornassem possível a realização dessas práticas. A bancada desenvolvida pode ser vista na Figura 2. Todas as oficinas práticas foram acompanhadas pelo tutor responsável pelo Programa de Educação Tutorial Engenharia Elétrica.

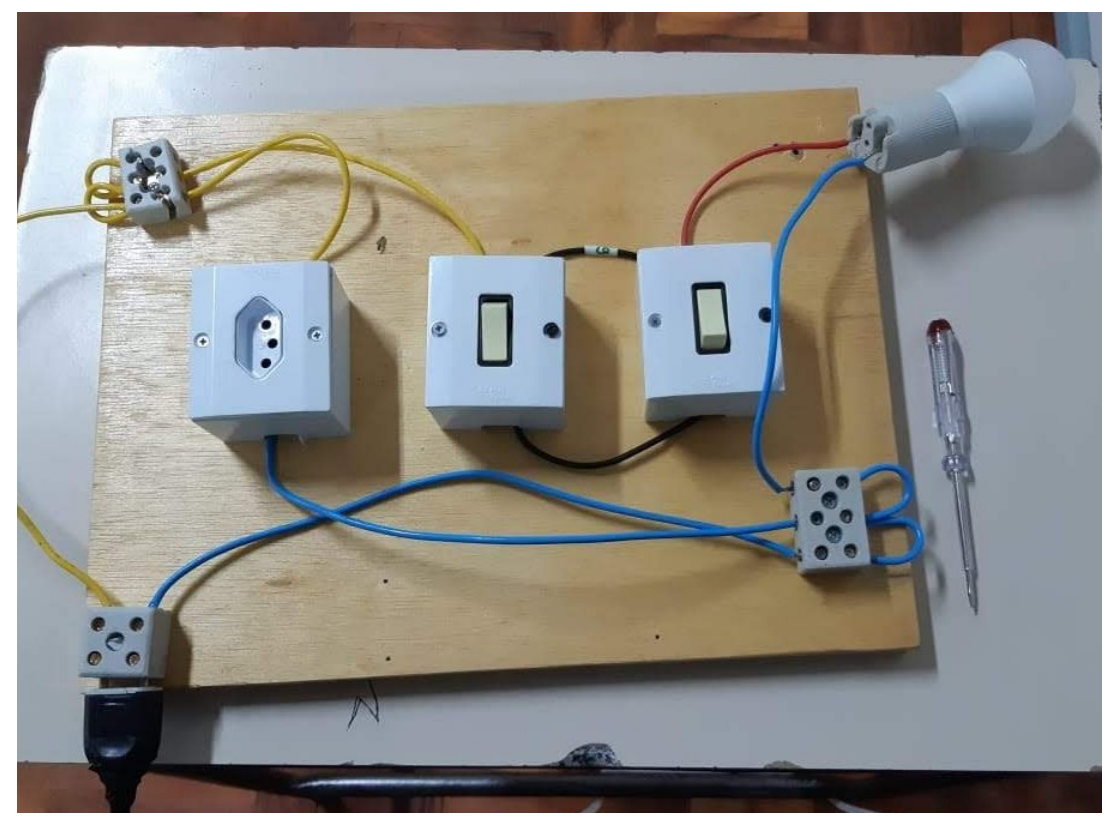

Figura 2. Bancada didática de instalações elétricas desenvolvida pelo PET-EE. 
Para cada aula foi elaborado um material teórico que foi posteriormente impresso e disponibilizado às mulheres participantes. Este material tinha formato de livreto e foi desenvolvido de maneira lúdica e em linguagem simples, com o objetivo de tonar mais interessante o contato das mulheres com os conceitos técnicos que abrangem a energia elétrica. Além disso, tais livretos possuíam grampo trilho de modo que a cada aula as mulheres conseguiam adicionar as folhas correspondentes ao conteúdo do dia. Na Figura 3 é possível visualizar os livretos desenvolvidos. Também, foram elaborados bottons, vendidos com o objetivo de arrecadar recursos para poder realizar a compra dos materiais utilizados. O modelo dos bottons desenvolvidos pode ser visualizado na Figura 4.

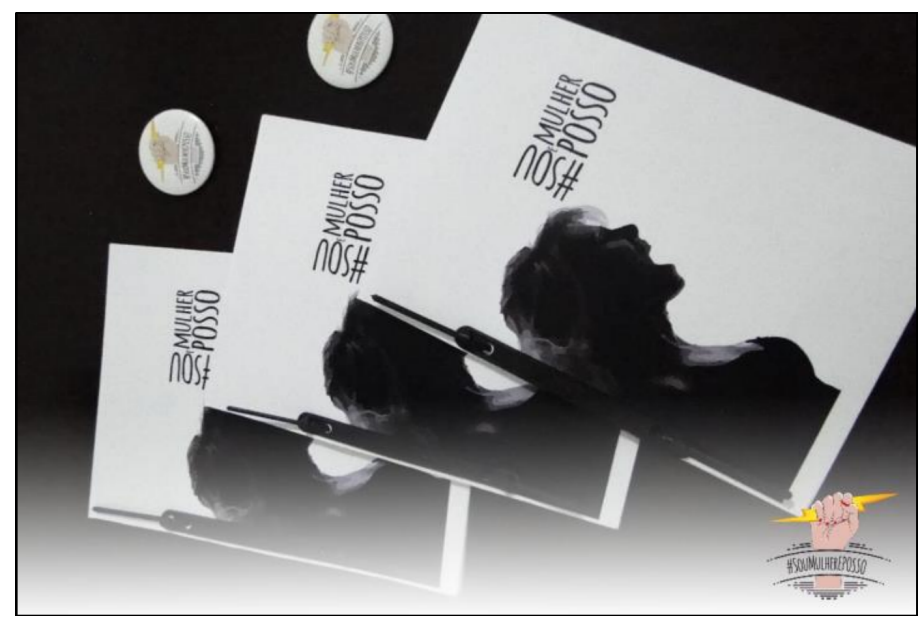

Figura 3. Livretos compostos por cinco módulos desenvolvidos pelo PET-EE.

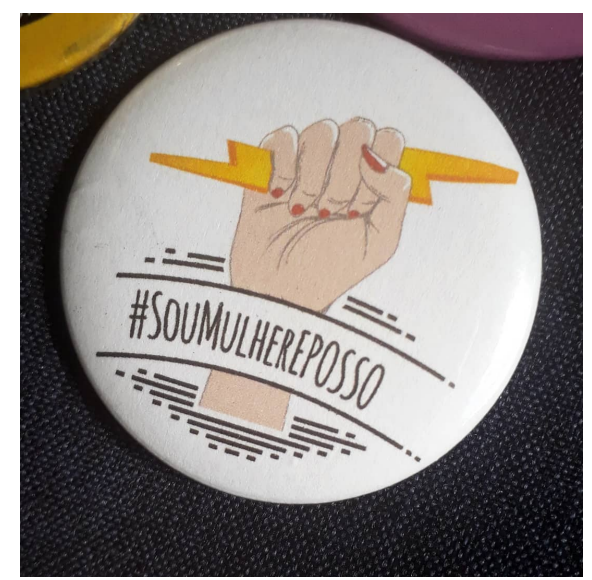

Figura 4. Modelo dos bottons desenvolvidos pelo PET-EE.

Durante as aulas teóricas optou-se por utilizar métodos didáticos que tornassem as mulheres mais participativas e interessadas. Em alguns momentos, contavam-se situações cotidianas relacionadas com o conteúdo transmitido, com o objetivo de torná-lo mais próximo da realidade. Também eram propostas algumas perguntas no decorrer da aula para verificar se as mulheres estavam entendendo o conteúdo, além de estimular o engajamento. Além disso, utilizou-se de experimentos e analogias com o objetivo de facilitar a aprendizagem. Um deles foi o uso de uma seringa com água, na qual a água representava a corrente elétrica e a pressão de um dos lados da seringa correspondia a tensão elétrica. Assim, mostrava-se de forma mais visual como funciona a diferença de potencial. 
No caso das mulheres que possuíam filhos, mas não havia quem os cuidasse no momento das aulas, era dado o suporte necessário para que elas pudessem participar. No próprio local havia uma sala com brinquedos e as estudantes que não estavam ministrando a aula naquele determinado dia ficavam responsáveis por atender as crianças caso necessário. Além de toda a abordagem técnica, tornou-se importante buscar uma maior conexão entre as envolvidas, para isso, realizaram-se intervalos em cada aula de forma que as pessoas pudessem confraternizar e compartilhar experiências entre si. Na Figura 5 é possível ver um momento de confraternização entre as participantes. No último encontro, cada uma das mulheres participantes recebeu uma foto que foi tirada no primeiro dia e um certificado simbólico.

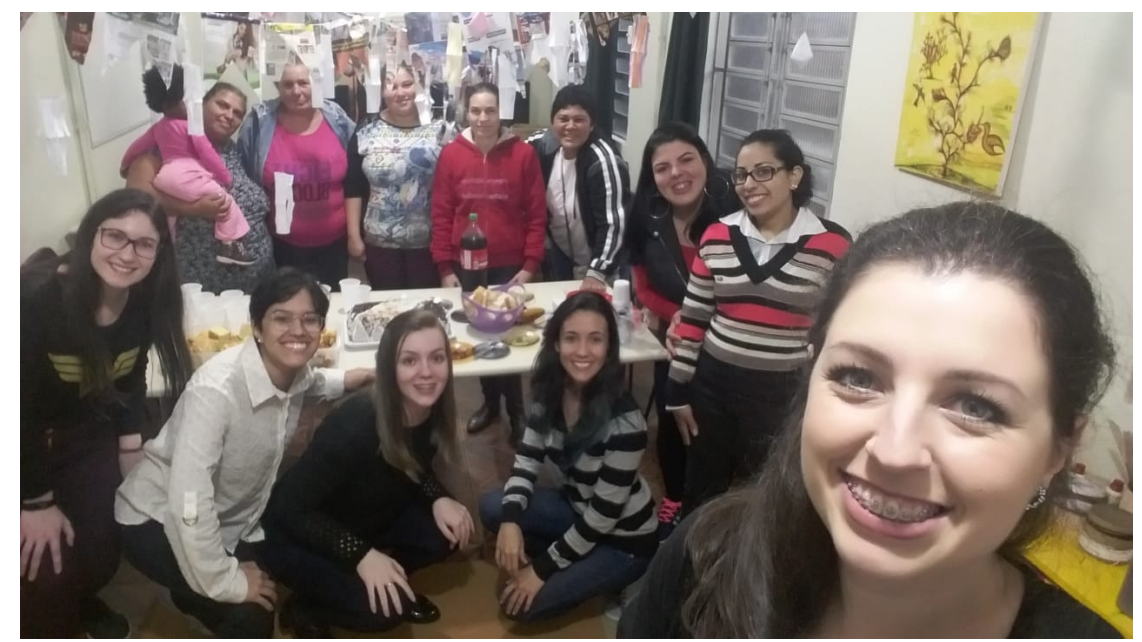

Figura 5. Momento de confraternização entre as participantes.

Além disso, no final do último encontro foi aplicado um questionário com o objetivo de entender e validar de que forma o projeto havia contribuído para as mulheres participantes.

\section{Resultados}

O projeto promoveu uma extensão eficiente e positiva entre a Universidade $\mathrm{Fe}$ deral de Santa Maria e a comunidade Nova Santa Marta. Foi possível aproximar conhecimentos acadêmicos ao cotidiano das moradoras da ocupação, possibilitando maior independência das mesmas na realização de montagens e reparos básicos de instalações elétricas residenciais com a devida segurança, além de se proporcionar o entendimento de como funciona o sistema de cobrança de energia e de que modo ele é exposto ao consumidor.

As aulas voltadas à educação popular, com ilustrações explicativas, analogias do conteúdo com o cotidiano das moradoras e execução prática dos conceitos, auxiliaram no aprendizado e proporcionaram grande participação das mulheres durante tais encontros. Estas contribuíram constantemente com dúvidas, respostas aos desafios propostos e relatos das suas experiências. Em vista disso, obteve-se consolidação efetiva dos assuntos abordados. Isso foi observado por meio da análise dos resultados de um formulário aplicado às mulheres ao final da última aula, referente ao nível de satisfação das aulas ministradas e que obteve um total de 5 respostas. 
Neste questionário, todas as mulheres consideraram o conteúdo abordado muito condizente e aplicável com a realidade das mesmas. Também, um percentual de $100 \%$ das participantes relatou que o conteúdo foi ministrado de forma muito compreensível, que as ilustrações auxiliaram muito no aprendizado, além de que os desafios propostos ajudaram muito na fixação do conteúdo. Isso reflete a importância e sucesso da forma que os assuntos foram expostos, sempre visando simplicidade e fácil compreensão.

Ainda, os quesitos de didática das ministrantes, importância do assunto tratado e material didático produzido foram elencados como "ótimo"pelas 5 mulheres participantes. O esclarecimento de dúvidas por parte das ministrantes foi avaliado como "ótimo"em 4 respostas e "bom"por uma das participantes. No geral, as aulas foram consideradas "ótimas"por todas as mulheres. Evidencia-se duas respostas descritivas deixadas no questionário em um espaço de coleta de feedback, sugestão ou elogio. Uma das participantes relatou "Adorei estar com vocês nesses dias que passamos juntas, aprendemos muito com as meninas"; enquanto que outra escreveu "Que as meninas continuem assim lindas, estudiosas e com muita vontade no coração de ajudar o próximo ensinando o que sabem".

Portanto, constata-se que o projeto possibilitou uma troca de experiências bastante enriquecedora, visto que ao mesmo tempo em que as alunas apresentaram os conceitos teóricos, também adquiriram vivências que colaboram na formação social e humana das mesmas. Assim, como pode ser visto na Figura 6, desenvolveu-se uma singela aproximação e amizade entre as envolvidas, despertando empatia e permitindo o contato entre pessoas de diferentes realidades sociais, ampliando-se horizontes e desmistificando determinados preconceitos. Além disso, devido ao fato deste projeto de extensão envolver uma realidade social pouco abordada na sociedade, foi necessário que as ministrantes aprendessem a levar o conhecimento de uma maneira mais acessível, diferente do habitual no meio acadêmico, e com isso, possibilitou-se adquirir experiências únicas de cunho educativo e social.

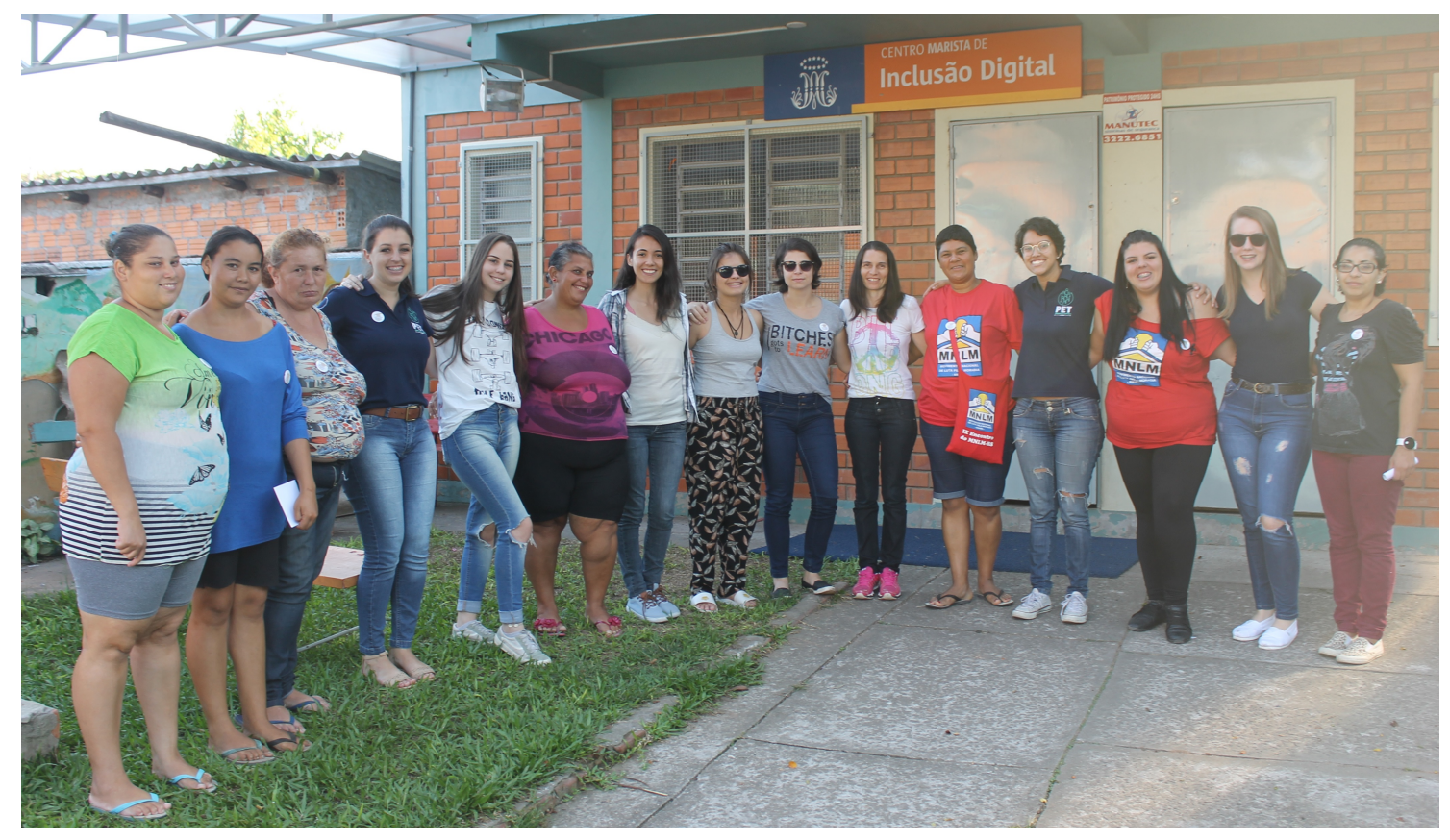

Figura 6. Algumas das alunas e mulheres participantes do projeto. 


\section{Considerações Finais}

O projeto de inclusão social e de gênero Sou Mulher e Posso atingiu os seus objetivos iniciais, pois promoveu uma interação efetiva entre a comunidade acadêmica da Universidade Federal de Santa Maria (UFSM) e a comunidade da ocupação Nova Santa Marta. Tal contato possibilitou a aquisição de conhecimentos por parte das moradoras sobre instalações elétricas residenciais, bem como desenvolvimento pessoal das acadêmicas envolvidas. Desta forma, proporcionou-se autonomia às mulheres da comunidade na realização de montagens e de reparos elétricos em suas próprias casas. Além disso, as alunas da universidade que estavam envolvidas no projeto fortaleceram sua formação humana, por meio do contato com diferentes realidades sociais, desenvolvendo-se senso crítico e empatia.

No início, o projeto contou com a participação de 10 mulheres. Infelizmente, no decorrer das aulas, algumas dessas participantes apresentaram obstáculos na vida pessoal que as impediram de continuar participando dos encontros. Tais desistências podem vir a ser um reflexo da realidade que elas estão inseridas, na qual as mesmas se veem muitas vezes obrigadas a abdicar de oportunidades em prol da família e do trabalho. Apesar disso, as atividades propostas conseguiram impactar um número significativo de mulheres. Assim sendo, contribuiu-se na modificação do cenário atual, fomentando a representatividade feminina e fornecendo maior visibilidade a ocupação Nova Santa Marta.

\section{Referências}

Lombardi, M. R. (2006). Engenheiras brasileiras: Inserção e limites de gênero no campo profissional. Cadernos de Pesquisa, pages 173-2002.

Saffioti, H. I. B. (2003). Gênero e patriarcado: violência contra as mulheres. in:venturini, g.; recaman, m.; oliveira, s. (orgs.). A mulher brasileira nos espaços público e privado.

Saffioti, H. I. B. (2013). A mulher na sociedade de classe - mito e realidade. Revista Gênero \& Direito, 1.

Scott, J. (1989). Gênero: uma categoria útil de análise histórica. Educação e Realidade, 15(2):5-22.

Thiollent, M. (1986). Metodologia da pesquisa-ação. Cortez: Autores Associados, 2th edition. 